\title{
A Building-Material Supply Chain Sustainable Operations under Fairness Concerns and Reference Price Benefits
}

\author{
Huimin Xiao, Youlei Xu (D), and Shiwei Li \\ Computer and Information Engineering College, Henan University of Economics and Law, Zhengzhou, China \\ Correspondence should be addressed to Youlei Xu; 18832019582@163.com
}

Received 12 February 2021; Revised 4 March 2021; Accepted 30 March 2021; Published 19 April 2021

Academic Editor: Wei Zhang

Copyright (c) 2021 Huimin Xiao et al. This is an open access article distributed under the Creative Commons Attribution License, which permits unrestricted use, distribution, and reproduction in any medium, provided the original work is properly cited.

\begin{abstract}
This paper incorporates fairness concerns and consumer reference price effects into a two-echelon building-material closed-loop supply chain consisting of a manufacturer and a retailer. By establishing four differential game models, we investigate the sustainable operations and cooperation of this supply chain. The four game models are a Nash noncooperative game, Stackelberg game with cost sharing, Stackelberg game with fairness concerns and cost sharing, and centralized decision model. By using dynamic models and optimal control theory, we obtain the two members' optimal equilibrium strategies in the supply chain. Analytical results show that the consumer reference price effect has a positive impact on the manufacturer's effort level, retailer's publicity level, and product brand goodwill, which can improve the supply chain performance. The retailer's partial commitment to cost sharing can enhance the production enthusiasm of the manufacturer, improve the brand reputation of the product, and enhance the two members' individual profitability. The distributional fairness concerns of the manufacturer not only prevent the manufacturer and retailer from achieving Pareto improvement but also lead to the decline of the manufacturer's effort level and profitability. The research conclusions of this paper can provide some insights into the cooperation and sustainable development of the supply chain.
\end{abstract}

\section{Introduction}

With the rapid development and promotion of e-commerce, enterprises have gradually entered the era of network economy, the uncertainty of the market environment has further increased, and the competition between enterprises has transformed into competition between the supply chains where the enterprises are located. As a result, the cooperation between supply chain companies has become particularly important. The supply chain contains various important elements, such as suppliers, manufacturers, distributors, and consumers. Among them, consumers are the most important sales targets of commodities, and their behavior characteristics directly affect the overall benefits of the enterprise and the supply chain. In the relevant literature, many scholars regard consumers as the most important influencing factor when studying the sustainable operation process of the supply chain, but they often ignore the cooperation among the companies in the supply chain. Some scholars regard consumers and enterprises as research objects at the same time. However, in their research, companies are completely rational with the goal of maximizing their own profits. However, in their research, enterprises are fully rational people who pursue their own profit maximization as the goal.

However, due to the influence of the environment and individual perceptions, the enterprise does not appear as a completely rational image. Therefore, when studying the sustainable operation of supply chain, this paper takes into account the behavior characteristics of consumers and the irrational behaviors among enterprises, such as the fairness of interest distribution, trying to analyze the following questions: (1) How does the manufacturer's fair concern behavior affect the supply chain effect? (2) Under the four different operating models, which mode can produce higher effects? (3) How does the importance of consumer reference price effects affect decision-making? From the perspective of cooperation in a supply chain consisting of only one 
manufacturer and one retailer, this paper takes fairness concerns and reference effects into consideration and provides some decision-making reference for promoting the long-term dynamic cooperation of supply chain members and improving overall performance.

\section{Literature Review}

In supply chain decision-making, fully considering the behavior characteristics of consumers is conducive to optimize the decision-making results of enterprises and help enterprises gain more market share.

In the study of consumer behavior, many scholars have found that consumer's reference price effect has a crucial influence on corporate decision-making. Winer [1] constructed an empirical model of brand selection on the effect of reference price, and the results showed that, when predicting the purchase rate of consumers, the model that considers the effect of reference price is better than the model that simply uses sales prices. Lin et al. [2] discussed the significant impact of reference price effects on supply chain cooperation and price promotion by establishing a differential game model. Research by Amit Mehra et al. [3] proved that consumer's reference price effect not only affects product differentiation and company profits but also affects product positioning. Chenavaz [4] found that consumer decision-making is affected by the reference price effect with the help of the Pontryagin principle of maximum value to prove the member's optimal quality strategy. Gavious [5] found that the supply chain effect with consumer's reference price effect is higher than the supply chain effect without reference price effect. Malekian [6] studied the effect of reference price effect on price promotion and national advertisers. The study found that consumer's reference price effect has an important impact on the promotion of advertising level and the increase of supply chain profits. Xu [7] discussed the impact of reference prices on the performance of three decentralized reverse channels and examined the impact of reference price effects on optimal strategies. Hsieh et al. [8] incorporated the reference price effect into the deteriorating inventory problem and established the best dynamic pricing model. The research by Zhang et al. [9] found that the reference price plays an important role in the customer's purchase decision and has an impact on the company's strategy and the most important pricing. The research by $\mathrm{He}$ et al. [10] demonstrated that the degree of green innovation in the supply chain will increase with the enhancement of consumer's reference price effect. It can be seen that the consumer's reference price effect directly or indirectly affects the final decision-making and economic effect of enterprises. When enterprises make strategic decisions, they will use the consumer's reference price effect as an influencing factor. However, in addition to consumers, the factors that affect corporate decision-making and profitability include partners or competing companies in the production supply chain, especially partners in the same supply chain.

At present, there are relatively few studies on introducing fairness concerns into corporate decision-making.
Fairness concerns mean that decision-makers compare their own profits and gains with a reference object and show aversion to the unfairness of income distribution, which directly affects the cooperation between enterprises. Economists represented by Kahneman [11] found that, in reality, high-level decision-makers are extremely concerned about the fairness of profit distribution. Povlov and Katok [12] also show through empirical research that fairness concerns can better explain retailer's pricing issues. Cui [13] and others introduced fairness concern behavior in the newsboy model, and the research proved that retailer's aversion to unfairness would have a negative impact on supply chain coordination. Ma et al. [14] found that fairness concerns will lead to a reduction in marketing efforts and costs, but, under certain conditions, they will narrow the profit gap between the two supply chain members. Zhang et al. [15] found that retailer's concerns about fairness affect wholesale prices and retail prices, and retailer's concerns about power and fairness jointly determine whether retailers benefit from fairness concerns. The research results of $\mathrm{Li}$ [16] found that the fair concern behavior of retailers can reduce the stability of the supply chain system more than the fair concern behavior of manufacturers. Zheng et al. [17] believe that in a fairer environment, the fair concern behavior of partners can bring about higher profits. It can be seen that companies as rational people are not only concerned about their own profits but also extremely concerned about the fairness of profit distribution. The degree of fairness concerns can directly affect the decision-making and benefits of each company in the supply chain. If the profit distribution is more even, it will stimulate the enthusiasm of the company to innovate and produce. On the contrary, it will make the company passive and slow down, resulting in a decline in the overall benefits of the production supply chain.

In view of this, this article considers the two factors of the reference price effect and fairness concern behavior of consumers that have an important impact in the supply chain and incorporates them into the unified dynamic differential game model. We try to analyze the following questions: (1) How does the manufacturer's fair concern behavior affect the supply chain effect? (2) Under the four different operating models, which mode can produce higher effects? (3) How does the importance of consumer reference price effects affect decision-making? From the perspective of cooperation in a supply chain consisting of only one manufacturer and one retailer, this paper takes fairness concerns and reference effects into consideration and provides some decision-making reference for promoting the long-term dynamic cooperation of supply chain members and improving overall performance.

\section{Model Construction and Solution}

\subsection{Model Construction and Symbol Description}

3.1.1. Model Description. This article assumes that the supply chain of building materials products consists of a retailer as a leader and a producer as a follower. Manufacturers can purchase professional equipment or research new 
technologies to improve the quality of building materials products and increase the degree of greenness of products. The efforts of building materials manufacturers directly affect the quality, degree of greenness, and brand reputation of products, which can further act on product sales. Building materials retailers can increase the brand reputation of products through certain publicity so that consumers have a deep impression of the products and thus increase product sales. Therefore, the publicity of building materials retailers directly affects product sales and brand reputation. This article chooses retailer as the leading party in the differential game and forms Stackelberg differential game with the manufacturer. The model is divided into four types, namely, the NASH noncooperative game; that is, building materials manufacturers and retailers strive to maximize their profits, and there is no cooperation or and mutual assistance. However, in order to encourage manufacturers to improve product quality and greenness, thereby increasing product awareness and product sales, retailers actively bear part of the costs for manufacturers, forming a Stackelberg differential game with retailers as the leader and manufacturers as followers. However, when making strategic decisions for companies, building materials manufacturers will not only consider their own interests but also pay great attention to the fairness of the distribution of interests with partners in the same supply chain. If the manufacturers' interest distribution is on the weak side, they will feel unfair and go slow passively. On the contrary, it will encourage producers to work harder and form a third model with fairness concerns. In centralized decision-making, the goal of decision-making is to maximize the benefits of the supply chain system, while fairness concerns the distribution of benefits within the supply chain, and the goal of each member is to maximize their own profits. Therefore, there is no fairness concern under centralized decision-making.

\subsubsection{Model Construction and Symbol Description}

Assumption 1. Because the effort cost of building materials manufacturers and the publicity cost of building materials retailers have the same convexity, referring to the setting of cost by Zhang [18], it is assumed that the effort cost of building materials manufacturers and the publicity cost of building materials retailers are quadratic functions of effort level and publicity level. Then the manufacturer's effort cost at time $t$ is $C_{n}(t)=(1 / 2) k_{1} E_{n}(t)^{2}$. The publicity cost of building materials retailers is $C_{n}(t)=(1 / 2) k_{1} E_{n}(t)^{2}$. Among them, $k_{1}>0$ and $k_{2}>0$ are the manufacturer's effort cost coefficient and the retailer's promotional cost coefficient, $E_{n}(t)$ represents the level of effort that manufacturers have made to improve product quality and greenness, and $E_{m}(t)$ represents the level of publicity made by retailers to enhance product branding.

Assumption 2. The effort level of building materials manufacturers and the publicity cost of retailers will not only improve the quality and green degree of products but also enhance the brand goodwill of products in the market, and the brand goodwill will continue to decline over time; that is, there is a certain natural decay rate. Refer to the dynamic model construction of brand goodwill by Ouardighi [19]. The dynamic model of brand goodwill can be established as follows:

$$
\dot{G}(t)=r_{n} E_{n}(t)+r_{m} E_{m}(t)-\delta G(t) .
$$

Among them, $G(0)=G_{0}$ is the initial brand goodwill. $r_{n}$ and $r_{m}$ are the influence coefficients of manufacturer's effort level and retailer's publicity level on brand goodwill, respectively, and $\delta$ is the natural decay rate of brand goodwill over time.

Assumption 3. Assuming that the reference effect of consumers is affected by the combination of consumer memory price and external stimulus and referring to the treatment of reference price effect by scholars such as Zhang [18] and Fibich [20], we can assume that the reference price of consumers in the supply chain of building materials production is dynamic, and its change rate is affected by the combination of price memory and brand goodwill as follows:

$$
\dot{R}(t)=\theta(P(t)-R(t))+\lambda G(t) .
$$

In the above equation, $\theta$ represents the consumer's "memory parameter." The larger the value of $\theta$ is, the lower the consumer's loyalty to the product is, because the consumer's memory of the product's past prices and purchase experience is very short.

$P(t)$ represents the market price of the product at time $t$, $R(t)$ represents the consumer's reference price at time $t$, and $\lambda$ is the influence coefficient of the product's brand goodwill on the consumer's reference price. If the brand goodwill is higher, the consumer's reference price will also increase. The improvement is consistent with the actual market. Among them, $R(0)=R_{0}$ is the initial reference price.

Assumption 4. The market sales of products are affected by the product price, brand goodwill, and consumer's reference price effect. Referring to the market demand set by Zhang [21], it can be assumed that the market demand function of the product is as follows:

$$
Q(t)=a-b p(t)+\alpha G(t)+\beta(R(t)-P(t)) .
$$

From the above equation, $a>0$ represents the inherent demand for the product in the market itself and is not affected by other factors. $b>0$ represents the influence coefficient of product price on demand. The higher the product price is, the less the market demand is, which is consistent with the market law. $\alpha>0$ represents the influence coefficient of product brand goodwill on market demand. $\beta>0$ represents the sensitivity coefficient of consumers to the difference between the reference price and the actual price. When $R(t)>P(t)$, consumers will feel that they are taking advantage of it, thereby increasing demand to obtain greater satisfaction. 
Assumption 5. In order to encourage manufacturers to make efforts to improve product quality and greenness, increase product awareness and brand reputation, and thereby increase sales, retailers take the initiative to bear a certain effort cost for manufacturers, and the cost coefficient is $\phi(t), 0<\phi(t)<1$.

Assumption 6. Assuming that both the manufacturer and the retailer of building materials have the same positive discount rate $\rho$, they pursue the maximization of their own effects in an infinite time range. In order to simplify the model, the inventory cost and shortage cost of retailers and manufacturers are set to zero.

In order to simplify the writing, the time $t$ is omitted when writing this article. The symbols and meanings of other parameters in the model are as follows.

$W$, manufacturer's wholesale price

$P$, Retailer's selling price

$\pi_{n}=W-C$, the marginal profit of the producer

$\pi_{m}=P-W$, retailer's profit margin

$\pi_{s}=P-C$, the marginal profit of the product

$\mathcal{E}$, the intensity of the manufacturer's concern for fairness

3.2. NASH Noncooperative Game. In the NASH noncooperative game, building materials manufacturers and retailers seek to maximize their own interests, and, when making decisions, they only consider how to increase their own profits. If the optimal level of the cooperative game in the supply chain is the upper limit of contract coordination, then the benefits of the NASH noncooperative game with no cost bearing and fairness concerns are the lower limit of contract coordination. Use superscript $D$ to represent the NASH noncooperative game model. At this time, the objective functions of the manufacturer and retailer are as follows:

$$
\begin{aligned}
& \max _{E_{n}>0} J_{N}^{D}=\int_{0}^{\infty} e^{-\rho t}\left[\pi_{n}(a-b p+\alpha G+\beta(R-P))-\frac{1}{2} k_{1} E_{n}^{2}\right] \mathrm{d} t, \\
& \max _{E_{m}>0} J_{N}^{D}=\int_{0}^{\infty} e^{-\rho t}\left[\pi_{m}(a-b p+\alpha G+\beta(R-P))-\frac{1}{2} k_{1} E_{m}^{2}\right] \mathrm{d} t .
\end{aligned}
$$

Theorem 1. The equilibrium result of the Nash noncooperative game is as follows.

(1) The best effort level and publicity level of building materials manufacturers and retailers are as follows:

$$
\begin{aligned}
& E_{n}^{D^{*}}=\frac{r_{n} \pi_{n}}{k_{1}(\rho+\delta)}\left(\alpha+\frac{\lambda \beta}{\rho+\theta}\right), \\
& E_{m}^{D^{*}}=\frac{r_{m} \pi_{m}}{k_{2}(\rho+\delta)}\left(\alpha+\frac{\lambda \beta}{\rho+\theta}\right) .
\end{aligned}
$$

(2) The optimal trajectory of brand goodwill is as follows:

$$
G^{D^{*}}(t)=H^{D}-\left(H^{D}-G_{0}\right) e^{-\delta t} \text {. }
$$

From the above equation,

$$
H^{D}=\left(\alpha+\frac{\lambda \beta}{\rho+\theta}\right)\left(\frac{r_{n}^{2} \pi_{n}}{\delta k_{1}(\rho+\delta)}+\frac{r_{m}^{2} \pi_{m}}{\delta k_{2}(\rho+\delta)}\right) .
$$

(3) The optimal effect functions of building materials manufacturers and retailers are as follows:

$$
\begin{aligned}
V_{N}^{D}= & \frac{\pi_{n}}{\rho+\delta}\left(\alpha+\frac{\lambda \beta}{\rho+\theta}\right) G+\frac{\pi_{n} \beta}{\rho+\theta} R+\frac{\pi_{n}(a-b p-\beta p)}{\rho}+\frac{\theta p \pi_{n} \beta}{\rho(\rho+\theta)}+\frac{r_{n}^{2} \pi_{n}^{2}}{2 k_{1} \rho(\rho+\delta)^{2}}\left(\alpha+\frac{\lambda \beta}{\rho+\theta}\right)^{2} \\
& +\frac{r_{n}^{2} \pi_{n} \pi_{m}}{2 k_{2} \rho(\rho+\delta)^{2}}\left(\alpha+\frac{\lambda \beta}{\rho+\theta}\right)^{2}, \\
V_{M}^{D}= & \frac{\pi_{M}}{\rho+\delta}\left(\alpha+\frac{\lambda \beta}{\rho+\theta}\right) G+\frac{\pi_{m} \beta}{\rho+\theta} R+\frac{\pi_{m}(a-b p-\beta p)}{\rho}+\frac{\theta p \pi_{m} \beta}{\rho(\rho+\theta)} \\
& +\frac{r_{m}^{2} \pi_{m}^{2}}{2 k_{2} \rho(\rho+\delta)^{2}}\left(\alpha+\frac{\lambda \beta}{\rho+\theta}\right)^{2}+\frac{r_{n}^{2} \pi_{n} \pi_{m}}{2 k_{2} \rho(\rho+\delta)^{2}}\left(\alpha+\frac{\lambda \beta}{\rho+\theta}\right)^{2} .
\end{aligned}
$$

Proof. See Appendix A.

Corollary 1. In the NASH noncooperative game, because $\left(\partial E_{n}^{D^{*}} / \partial \theta\right)<0$, that is, the consumer's sensitivity to past prices and purchase experience, will affect the producer's effort level, and this effect is negatively correlated, the higher the consumer sensitivity coefficient, the lower the producer's level of effort; and, by $\left(\partial E_{n}^{D^{*}} / \partial k_{1}\right)<0,\left(\partial E_{n}^{D^{*}} / \partial \rho\right)<0,\left(\partial E_{n}^{D^{*}} / \partial \delta\right)<0$, it can be concluded that the manufacturer's effort level will decrease with the increase of the manufacturer's effort cost coefficient, discount rate, and natural decay rate of brand goodwill. Because of $\left(\partial E_{n}^{D^{*}} / \partial \pi_{n}\right)>0,\left(\partial E_{n}^{D^{*}} / \partial r_{n}\right)>0,\left(\partial E_{n}^{D^{*}} / \partial \alpha\right)>$ $0,\left(\partial E_{n}^{D^{*}} / \partial \beta\right)>0$, the level of effort of building materials manufacturers is positively correlated with factors such as 
$\pi_{n}, r_{n}, \alpha$, and $\lambda$. Moreover, the impact coefficient $\beta$ of consumer's reference price effect on demand is also positively correlated with manufacturer's effort level. This is because manufacturer's effort level can improve product quality and green degree and further improve brand reputation and consumer's reference price. The higher the consumer's reference price effect is, the greater satisfaction can be obtained, thus increasing demand. This has stimulated manufacturers to improve their efforts.

Corollary 2. Similarly, the following results can be obtained:

$$
\begin{aligned}
& \frac{\partial E_{m}^{D^{*}}}{\partial \pi_{m}}>0, \\
& \frac{\partial E_{m}^{D^{*}}}{\partial r_{m}}>0, \\
& \frac{\partial E_{m}^{D^{*}}}{\partial \alpha}>0, \\
& \frac{\partial E_{m}^{D^{*}}}{\partial \lambda}>0, \\
& \frac{\partial E_{m}^{D^{*}}}{\partial \beta}>0, \\
& \frac{\partial E_{m}^{D^{*}}}{\partial k_{2}}<0 \frac{\partial E_{m}^{D^{*}}}{\partial \rho}<0, \\
& \frac{\partial E_{m}^{D^{*}}}{\partial \delta}<0, \\
& \frac{\partial E_{m}^{D^{*}}}{\partial \theta}<0 .
\end{aligned}
$$

Because retailers and manufacturers have different cost coefficients and profit margins, there are only differences between these two positive and negative correlation factors, and the other positive and negative correlation factors are the same.
Corollary 3. In NASH noncooperative game, the stable value of product brand goodwill dynamic model is positively correlated with one of the following factors. They are the influence coefficients $r_{n}$ and $r_{m}$ of effort level of building materials manufacturers and publicity level of retailers on goodwill, the influence coefficient $\beta$ of consumer reference price effect on demand, the influence coefficient $\alpha$ of product goodwill on demand, the influence coefficient $\lambda$ of brand goodwill on consumer reference price, and the marginal profits $\pi_{n}$ and $\pi_{m}$ of manufacturers and retailers. It is negatively correlated with the natural decay rate of brand goodwill $\delta$, discount factor $\rho$, cost coefficients $k_{1}$ and $k_{2}$ of manufacturers and retailers, and sensitivity coefficient $\theta$ of consumers to product price and purchase experience. Moreover, the optimal trajectory model of product brand goodwill is monotonic transformation. When $\mathrm{H}^{u}>G$, brand goodwill will increase with the increase of time. When $\mathrm{H}^{u}<G$, brand goodwill will decrease monotonously with the increase of time. When $H^{u}=G$, brand goodwill will be a constant.

3.3. Stackelberg Game with Cost Sharing. When considering the issue of cost sharing, building materials retailers in order to encourage manufacturers to do their best to improve the quality and greenness of their products, building materials retailers take the initiative to provide a certain percentage of subsidies to manufacturer's efforts. From the perspective of long-term dynamics, the decision-making of supply chain investment between building materials retailers and manufacturers constitutes a Stackelberg game model, and this game model is dominated by retailers, and the superscript A is used to represent the case considering cost sharing.

Building materials retailers and manufacturers aim to maximize their own effects when making decisions. The decision-making process is divided into two stages. In the first stage, building materials retailers determine their own publicity level and cost sharing proportion for manufacturers. In the second stage, according to the retailer's publicity level and cost sharing ratio, the building material manufacturer determines the best level of its own effort. Therefore, the objective functions of manufacturer and retailer are as follows:

$$
\begin{aligned}
& \max _{E_{n}>0} J_{N}^{A}=\int_{0}^{\infty} e^{-\rho t}\left[\pi_{n}(a-b p+\alpha G+\beta(R-P))-\frac{(1-\phi)}{2} k_{1} E_{n}^{2}\right] \mathrm{d} t \\
& \max _{E_{m}>0} J_{M}^{A}=\int_{0}^{\infty} e^{-\rho t}\left[\pi_{m}(a-b p+\alpha G+\beta(R-P))-\frac{1}{2} k_{2} E_{m}^{2}-\frac{\phi}{2} k_{1} E_{n}^{2}\right] \mathrm{d} t .
\end{aligned}
$$


Theorem 2. In a Stackelberg game with cost bearing, the equilibrium result is as follows.

(1) The optimal effort cost, publicity cost, and share ratio of building materials manufacturers and retailers are as follows:

$$
\left\{\begin{array}{l}
E_{n}^{A^{*}}=\frac{r_{n}\left(2 \pi_{m}+\pi_{n}\right)}{2 k_{1}(\rho+\delta)}\left(\alpha+\frac{\lambda \beta}{\rho+\theta}\right), \\
E_{m}^{A^{*}}=\frac{r_{m} \pi_{m}}{2 k_{2}(\rho+\delta)}\left(\alpha+\frac{\lambda \beta}{\rho+\theta}\right), \\
\phi=\frac{2 \pi_{m}-\pi_{n}}{\pi_{m}+\pi_{n}}
\end{array}\right.
$$

(2) The optimal trajectory function of the dynamic model of product brand goodwill is as follows:

$$
G^{A^{*}}(t)=H^{A}-\left(H^{A}-G_{0}\right) e^{-\delta t} \text {. }
$$

From the above equation,

$$
H^{A}=\left(\alpha+\frac{\lambda \beta}{\rho+\theta}\right)\left(\frac{r_{n}\left(2 \pi_{m}+\pi_{n}\right)}{2 k_{1} \delta(\rho+\delta)}+\frac{r_{m}^{2} \pi_{m}}{k_{2} \delta(\rho+\delta)}\right) .
$$

(3) The optimal effect functions of building materials manufacturers and retailers are as follows:

$$
\begin{aligned}
V_{N}^{A^{*}}= & \frac{\pi_{n}}{\rho+\delta}\left(\alpha+\frac{\lambda \beta}{\rho+\theta}\right) G+\frac{\pi_{n} \beta}{\rho+\theta} R+\frac{\pi_{n}(a-b p-\beta p)}{\rho}+\frac{\theta p \pi_{n} \beta}{\rho(\rho+\theta)} \\
& +\frac{r_{n}^{2} \pi\left(2 \pi_{m}+\pi_{n}\right)}{4 k_{1} \rho(\rho+\delta)^{2}}\left(\alpha+\frac{\lambda \beta}{\rho+\theta}\right)^{2}+\frac{r_{m}^{2} \pi_{n} \pi_{m}}{k_{2} \rho(\rho+\delta)^{2}}\left(\alpha+\frac{\lambda \beta}{\rho+\theta}\right)^{2}, \\
V_{N}^{A^{*}}= & \frac{\pi_{m}}{\rho+\delta}\left(\alpha+\frac{\lambda \beta}{\rho+\theta}\right) G+\frac{\pi_{m} \beta}{\rho+\theta} R+\frac{\pi_{m}(a-b p-\beta p)}{\rho}+\frac{\theta p \pi_{m} \beta}{\rho(\rho+\theta)} \\
& +\frac{r_{m}^{2} \pi_{m}^{2}}{4 k_{2} \rho(\rho+\delta)^{2}}\left(\alpha+\frac{\lambda \beta}{\rho+\theta}\right)^{2}+\frac{r_{n}^{2}\left(2 \pi_{m}+\pi_{m}\right)^{2}}{2 k_{1} \rho(\rho+\delta)^{2}}\left(\alpha+\frac{\lambda \beta}{\rho+\theta}\right)^{2} .
\end{aligned}
$$

The proof of Theorem 2 is similar to the proof of Theorem 1 , so we will not repeat it here.

From Theorem 2, the following inferences can be obtained.

Corollary 4. Building materials retailers are willing to bear part of the cost in order to encourage manufacturers to improve and upgrade their products, but there are implicit conditions. Only when the marginal profits of retailers and manufacturers meet the condition of $2 \pi_{m}>\pi_{n}$ are building materials retailers willing to bear part of the cost for manufacturers. Moreover, the retailer's cost share is positively correlated with the retailer's marginal profit $\pi_{m}$ and negatively correlated with the manufacturer's marginal profit $\pi_{n}$.

3.4. The Stackelberg Game Where Manufacturers Have Fair Concerns about Profit Distribution. As a rational person, a building material manufacturer not only pays attention to its own interests but also pays attention to the fairness of profit distribution with retailers in the same supply chain. However, this fairness concern is the subjective thinking of the manufacturer, and the building material retailer cannot know whether the manufacturer has fair concern for profit distribution. Therefore, in the minds of retailers, the objective function of manufacturers is still as follows:

$$
\max _{E_{n}>0} J_{N_{1}}^{C}=\int_{0}^{\infty} e^{-\rho t}\left[\pi_{n} a-b p+\alpha G+\beta(R-P)-\frac{(1-\phi)}{2} k_{1} E_{n}^{2}\right] \mathrm{d} t .
$$

Building materials retailers are based on the fairness of manufacturer; set your own profit function as follows:

$$
\max _{E_{m}>0} J_{M}^{C}=\int_{0}^{\infty} e^{-\rho t}\left[\pi_{m}(a-b p+\alpha G+\beta(R-P))-\frac{1}{2} k_{2} E_{m}^{2}-\frac{\phi}{2} k_{1} E_{n}^{2}\right] \mathrm{d} t
$$

However, because building materials manufacturers have fair concerns about profit distribution, what manufacturers pursue is no longer their own profit maximization but the utility maximization brought about by the fairness of profit distribution. The formula for maximizing utility is 


$$
\left\{\begin{array}{c}
\pi_{n}(a-b p+\alpha G+\beta(R-P))-\frac{(1-\phi)}{2} k_{1} E_{n}^{2} \\
\max _{E_{n}>0} J_{N}^{C}=\int_{0}^{\infty} e^{-\rho t}+\varepsilon\left[\begin{array}{c}
\pi_{n}(a-b p+\alpha G+\beta(R-P))-\frac{(1-\phi)}{2} k_{1} E_{n}^{2} \\
-\left(\pi_{m}(a-b p+\alpha G+\beta(R-P))-\frac{1}{2} k_{2} E_{m}^{2}-\frac{\phi}{2} k_{1} E_{n}^{2}\right)
\end{array}\right] \mathrm{d} t
\end{array}\right\} .
$$

When the retailers are in the advantage of profit distribution, the retailers will pay more efforts to improve their own efficiency. Otherwise, they will go slow and reduce efficiency. After sorting, the following formula can be obtained:

$$
\max _{E_{n}>0} J_{N}^{C}=\int_{0}^{\infty} e^{-\rho t}(1+\varepsilon)\left[\begin{array}{c}
\pi_{n}(a-b p+\alpha G+\beta(R-P))-\frac{(1-\phi)}{2} k_{1} E_{n}^{2} \\
-\varepsilon\left[\pi_{m}(a-b p+\alpha G+\beta(R-P))-\frac{1}{2} k_{2} E_{m}^{2}-\frac{\phi}{2} k_{1} E_{n}^{2}\right]
\end{array}\right] \mathrm{d} t .
$$

Theorem 3. In the Stackelberg game with fairness concerns and cost bearing, the following results can be obtained:
(1) The equilibrium results of building materials manufacturers and retailers are as follows:

$$
\left\{\begin{array}{l}
E_{n}^{C^{*}}=\frac{r_{n}}{k_{1}(\rho+\delta)}\left(\alpha+\frac{\lambda \beta}{\rho+\theta}\right) \frac{\left(\pi_{n}+\varepsilon \pi_{n}-\varepsilon \pi_{m}\right)\left(2 \pi_{m}+\pi_{n}\right)}{3 \varepsilon \pi_{n}-2 \varepsilon \pi_{m}+2 \pi_{n}} \\
E_{m}^{C^{*}}=\frac{r_{m} \pi_{m}}{k_{2}(\rho+\delta)}\left(\alpha+\frac{\lambda \beta}{\rho+\theta}\right) \\
\phi=\frac{2 \pi_{m}-\pi_{n}}{2 \pi_{m}+\pi_{n}}
\end{array}\right.
$$

(2) The moving track model of brand goodwill is as follows:

$$
G^{C *}(t)=H^{C}-\left(H^{C}-G_{0}\right) e^{-\delta t}
$$

From the above equation,

$$
H^{C}=\frac{r_{n}^{2}}{k_{1} \delta(\rho+\delta)}\left(\alpha+\frac{\lambda \beta}{\rho+\theta}\right) \frac{\left(\pi_{n}+\varepsilon \pi_{n}-\varepsilon \pi_{m}\right)\left(2 \pi_{m}+\pi_{n}\right)}{\left(3 \varepsilon \pi_{n}-2 \varepsilon \pi_{m}+2 \pi_{n}\right)}+\frac{r_{m}^{2} \pi_{m}}{k_{2} \delta(\rho+\delta)}\left(\alpha+\frac{\lambda \beta}{\rho+\theta}\right) .
$$


(3) The real optimal income function of building materials manufacturer is as follows:

$$
\begin{aligned}
V_{n}^{C^{*}}= & \frac{1}{\rho+\delta}\left(\alpha+\frac{\lambda \beta}{\rho+\theta}\right)\left(\pi_{n}+\varepsilon \pi_{n}-\pi_{m}\right) G+\frac{\pi_{n} \beta+\varepsilon \beta-\varepsilon \pi_{m} \beta}{\rho+\theta} R \\
& +\frac{1}{\rho}\left[\left(\pi_{n}+\varepsilon \pi_{n}-\varepsilon \pi_{m}\right)\left(a-b p-\beta-+\frac{\theta \beta p}{\rho+\theta}\right)+\frac{r_{m}^{2} \pi_{m}}{2 k_{2}(\rho+\delta)^{2}}\left(\alpha+\frac{\lambda \beta}{\rho+\theta}\right)^{2}\left(2 \pi_{n}+2 \varepsilon \pi_{n}-\varepsilon \pi_{m}\right)\right] \\
& +\frac{1}{\rho} \frac{r_{n}^{2}}{2 k_{1}(\rho+\delta)}\left(\alpha+\frac{\lambda \beta}{\rho+\theta}\right)^{2}\left(\pi_{n}+\varepsilon \pi_{n}-\varepsilon \pi_{m}\right)^{2} \frac{\left(2 \pi_{m}+\pi_{n}\right)}{3 \varepsilon \pi_{n}-2 \pi_{m}+2 \pi_{n}} .
\end{aligned}
$$

The optimal effect function of building materials retailers is as follows:

$$
\begin{aligned}
V_{m}^{C^{*}}= & \frac{1}{\rho+\delta}\left(\alpha+\frac{\lambda \beta}{\rho+\theta}\right) G+\frac{\pi_{m} \beta}{\rho+\theta} R+\frac{\pi_{m}(a-b p-\beta p)}{\rho}+\frac{\theta p \pi_{m} \beta}{\rho(\rho+\theta)}+\frac{r_{m}^{2} \pi_{m}}{2 \rho k_{2}(\rho+\delta)^{2}}\left(\alpha+\frac{\lambda \beta}{\rho+\theta}\right)^{2} \\
& +\frac{r_{n}^{2}}{\rho k_{1}(\rho+\delta)^{2}}\left(\alpha+\frac{\lambda \beta}{\rho+\theta}\right)^{2} \frac{\left(\pi_{n}+\varepsilon \pi_{n}-\varepsilon \pi_{m}\right)\left(2 \pi_{m}+\pi_{n}\right)\left(\pi_{n}^{2}+\varepsilon \pi_{n}^{2}\right)}{3 \varepsilon \pi_{n}-2 \varepsilon \pi_{m}+2 \pi_{n}} .
\end{aligned}
$$

The optimal effect function of building materials manufacturers is as follows:

$$
\begin{aligned}
V_{N_{1}}^{C *}= & \frac{\pi_{n}}{\rho+\delta}\left(\alpha+\frac{\lambda \beta}{\rho+\theta}\right) G+\frac{\pi_{n} \beta}{\rho+\theta} R+\frac{\pi_{n}(a-b p-\beta p)}{\rho}+\frac{\theta p \pi_{n} \beta}{\rho(\rho+\theta)}+\frac{r_{m}^{2} \pi_{m} \pi_{n}}{\rho k_{2}(\rho+\delta)^{2}}\left(\alpha+\frac{\lambda \beta}{\rho+\theta}\right)^{2} \\
& -\frac{r_{n}^{2}}{\rho k_{1}(\rho+\delta)^{2}}\left(\alpha+\frac{\lambda \beta}{\rho+\theta}\right)^{2} \frac{\left(\pi_{n}^{2}+\varepsilon \pi_{n}^{2}-\varepsilon \pi_{m} \pi_{n}\right)\left(2 \pi_{m}+\pi_{n}\right)}{3 \varepsilon \pi_{n}-2 \varepsilon \pi_{m}+2 \pi_{n}}\left(\frac{\varepsilon \pi_{m}-2 \varepsilon \pi_{n}-\pi_{n}}{3\left(\varepsilon \pi_{n}-2 \varepsilon \pi_{m}+2 \pi_{n}\right)}\right) .
\end{aligned}
$$

The following inference can be obtained from Theorem 3.

Corollary 5. The building material manufacturer's fair concern for profit distribution will not affect the retailer's publicity level, because the manufacturer will have fairness negative effects because of jealousy of the retailer, but the manufacturer's fairness concern intensity information is not public information. When making a decision on the level of publicity, the retailer does not know the manufacturer's fairness concerns, so the retailer's publicity level is not affected by the manufacturer's fairness concerns.

Corollary 6. The effort level of building materials manufacturers will be affected by their own intensity of fairness concerns, and because $\left(\partial E_{n}^{C^{*}} / \partial \varepsilon\right)<0$, as the intensity of fairness concerns increases, the effort level of manufacturers will decrease. This is because manufacturers are jealous of retailer's high profits. Manufacturer's dissatisfaction with profit distribution and concern about fairness lead to negative production, and they are not willing to spend higher costs to improve product's quality and output.

3.5. Centralized Decision. In the case of centralized decisionmaking, the decision goal is to maximize the overall benefits of the building materials market supply chain. However, the intensity of the fairness concern of building materials manufacturers is to seek the fairness of the distribution of benefits, and it is the goal of the internal members of the supply chain to maximize their own interests. Therefore, under centralized decision-making, manufacturers do not have fair concerns.

Under centralized decision-making, building materials manufacturers and retailers work together to maximize the overall benefits of the system as the goal. The superscript $S$ represents centralized decision-making. At this time, the objective function of the supply chain is as follows: 


$$
\max _{E_{n}>0, E_{m}>0} J_{H}^{S}=\int_{0}^{\infty} e^{-\rho t}\left[\pi_{s}(a-b p+\alpha G+\beta(R-P))-\frac{1}{2} k_{1} E_{n}^{2}-\frac{1}{2} k_{2} E_{m}^{2}\right] \mathrm{d} t .
$$

Theorem 4. In the centralized decision game model, the following results can be obtained:

(1) The equilibrium results of building materials manufacturers and retailers are as follows:

$$
\begin{aligned}
& E_{n}^{s^{*}}=\frac{r_{n} \pi_{s}}{k_{1}(\rho+\delta)}\left(\alpha+\frac{\lambda \beta}{\rho+\theta}\right) \\
& E_{m}^{s^{*}}=\frac{r_{m} \pi_{s}}{k_{2}(\rho+\delta)}\left(\alpha+\frac{\lambda \beta}{\rho+\theta}\right) .
\end{aligned}
$$

(2) The moving track model of brand goodwill is as follows:

$$
G^{S^{*}}(t)=H^{S}-\left(H^{S}-G_{0}\right) e^{-\delta t} .
$$

From the above equation,

$$
H^{S}=\left(\alpha+\frac{\lambda \beta}{\rho+\theta}\right)\left(\frac{r_{n}^{2} \pi_{S}}{\delta k_{1}(\rho+\delta)}\right)+\left(\frac{r_{m}^{2} \pi_{S}}{\delta k_{2}(\rho+\delta)}\right) .
$$

(3) The optimal effect function of supply chain is as follows:

$$
\begin{aligned}
V_{H}^{S^{*}}= & \frac{\pi_{s}}{\rho+\delta}\left(\alpha+\frac{\lambda \beta}{\rho+\theta}\right) G+\frac{\beta \pi_{s}}{\rho+\theta} R+\frac{\pi_{s}(a-b p-\beta p)}{\rho} \\
& +\frac{\theta \beta \pi_{s} p}{\rho(\rho+\theta)}+\frac{\pi_{s}^{2}}{\rho(\rho+\delta)^{2}}\left(\frac{r_{n}^{2}}{2 k_{1}}+\frac{r_{m}^{2}}{2 k_{2}}\right)\left(\alpha+\frac{\lambda \beta}{\rho+\theta}\right)^{2} .
\end{aligned}
$$

\section{Comparison and Analysis}

Comparing and analyzing the inputs and benefits of building materials manufacturers and retailers in the production supply chain under different decisions, the following inferences can be obtained.

Corollary 7. According to formulas (5), (12), (19), and (26), we can clearly get $E_{m}^{S^{*}}>E_{m}^{D^{*}}=E_{m}^{A^{*}}=E_{m}^{C^{*}}$. Under the centralized decision-making, the retailer's publicity level can reach the best condition.

Corollary 8. When the strength of fairness concerns of the building material manufacturer $\varepsilon=0$, there is $E_{n}^{C^{*}}=E_{n}^{A^{*}}$, so, in case 2 and case 3 , the levels of effort of the manufacturer are the same. When $0<\varepsilon<1$, the manufacturer is more concerned about the fairness of profit distribution, and, with the increase of fairness concern intensity $\varepsilon$, the manufacturer's effort level $E_{n}^{C^{*}}$ will also decrease, so $E_{n}^{C^{*}}<E_{n}^{A^{*}}$. Therefore, when $\varepsilon=0$, there is $E_{n}^{S^{*}}>E_{n}^{C^{*}}=E_{n}^{A^{*}}>E_{n}^{D^{*}}$. When $0<\varepsilon<1$, there is
$E_{n}^{S^{*}}>E_{n}^{A^{*}}>E_{n}^{C^{*}}>E_{n}^{D^{*}}$. The fairness concerns of producers not only are detrimental to improving their own efforts but also reduce the production effect and income.

Corollary 9. From equations (6), (14), (20), and (27), we can $\operatorname{get} G^{S *}(t)>G^{A^{*}}(t)>G^{C *}(t)>G^{D *}(t)$. Under the centralized decision-making, the stable value of brand goodwill is still in the best value, and the stable value of brand goodwill under the Nash noncooperative game is in the lowest state. The cost sharing of retailers to manufacturers is conducive to the further improvement of product brand goodwill, which can make Pareto improvement. However, the manufacturer's concern about the fairness of profit distribution will lead to negative production and reduce brand goodwill.

\section{Simulation Analysis}

In the standardized supply chain of building materials market, the ultimate goal of building materials manufacturers and retailers is to achieve the maximization of social and economic effects. In order to better verify the authenticity and reliability of the above theory, this article uses MATLAB software for numerical simulation analysis to verify the effectiveness of the model. Let the reference values be as follows:

$$
\begin{aligned}
\pi_{n} & =0.8, \\
\pi_{m} & =1, \\
r_{n} & =0.9, \\
r_{m} & =1.2, \\
k_{1} & =1, \\
k_{2} & =2, \\
\theta & =0.7, \\
\delta & =0.8, \\
\lambda & =0.5, \\
\beta & =0.7, \\
\alpha & =0.6, \\
a & =20 \\
b & =1, \\
p & =5, \\
G(0) & =0, \\
R(0) & =5, \\
\rho & =0.3 .
\end{aligned}
$$

This article only selects some parameters for sensitivity analysis. Substitute the benchmark parameters into the corresponding model and draw the relevant graphs. Take $t \in[0,10]$, and draw the optimal trajectory graph of the 


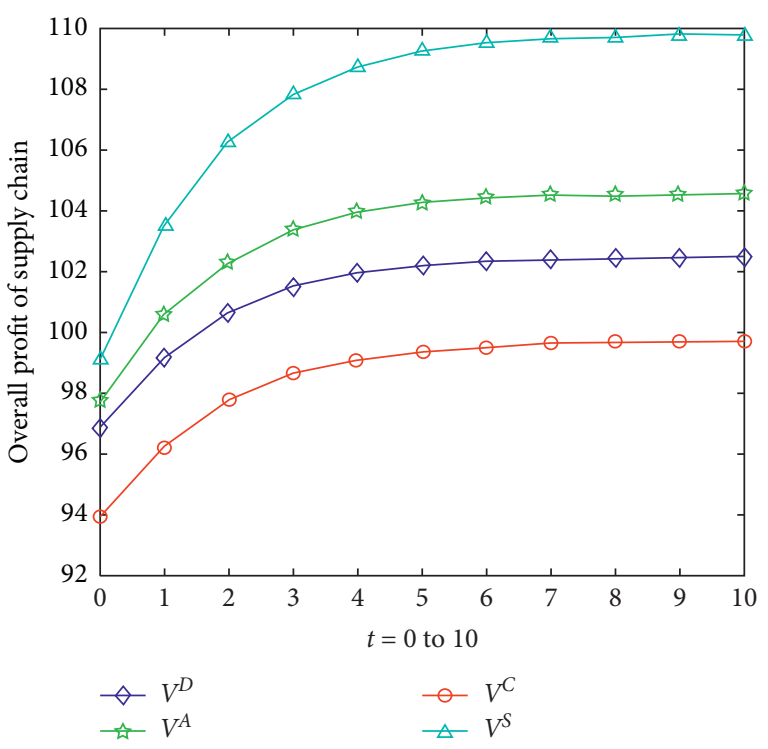

FIGURE 1: The optimal trajectory of supply chain profits under benchmark parameters.

overall benefits of the supply chain under four different decision-making situations, as shown in the figure below.

According to Figure 1, it can be clearly observed that, with the passage of time $t$, the overall benefits of the supply chain also increase, and the supply chain effect under centralized decision-making is much higher than the overall supply chain effect under the other three situations. The part of the cost of building materials retailers can further help realize the Pareto improvement of the supply chain. However, when manufacturers hold a fair concern attitude towards profit distribution (in order to make the overall gap between supply chains more intuitive, this paper sets the fairness concern degree of retailers as $50 \%$ ), the overall efficiency of the supply chain declines significantly.

With the help of Figure 2, we can more clearly understand the impact of fairness concerns on supply chain effects. With the increase in the strength $\varepsilon$ of building materials manufacturers' concerns about the fairness of profit distribution, it has had a serious negative impact on the manufacturers' own operating profits. This is because the retailers obtain higher profits in the process of brand promotion and sales. It has aroused the jealousy of building materials manufacturers and caused them to be unwilling to spend a higher level of effort to improve product quality and negatively sabotage work, which will affect their own income. However, retailers are not affected by the manufacturer's fairness concern psychology, because fairness concern is the manufacturer's subjective thinking. Retailers cannot understand the manufacture's subjective thinking well. When retailers make decisions, they will assume that the manufacturer's concern for fairness is zero.

Figure 3 reflects the impact of consumer reference price effects on brand goodwill, and, in the four game models, the brand goodwill under centralized decision-

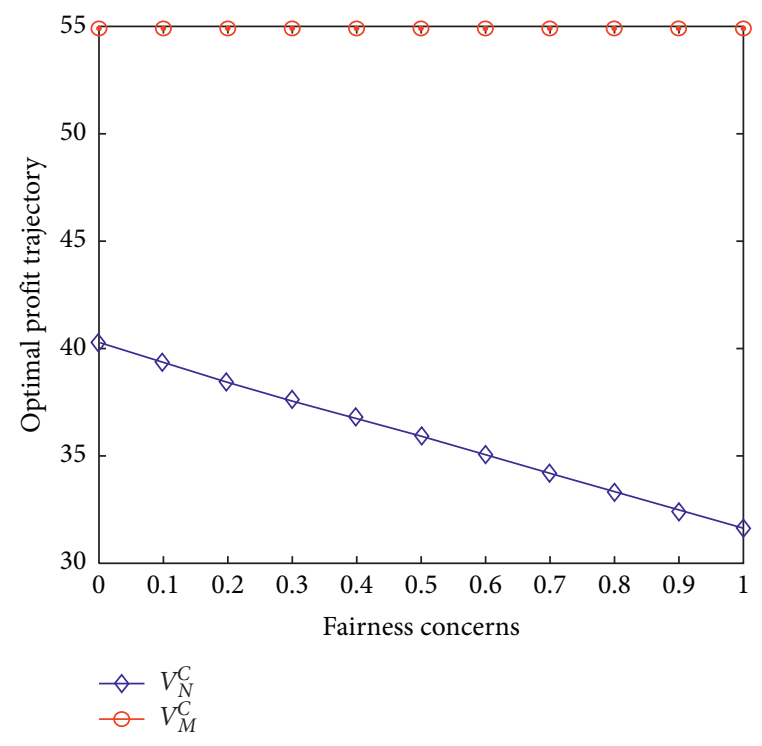

Figure 2: Profit trend chart under fairness concerns.

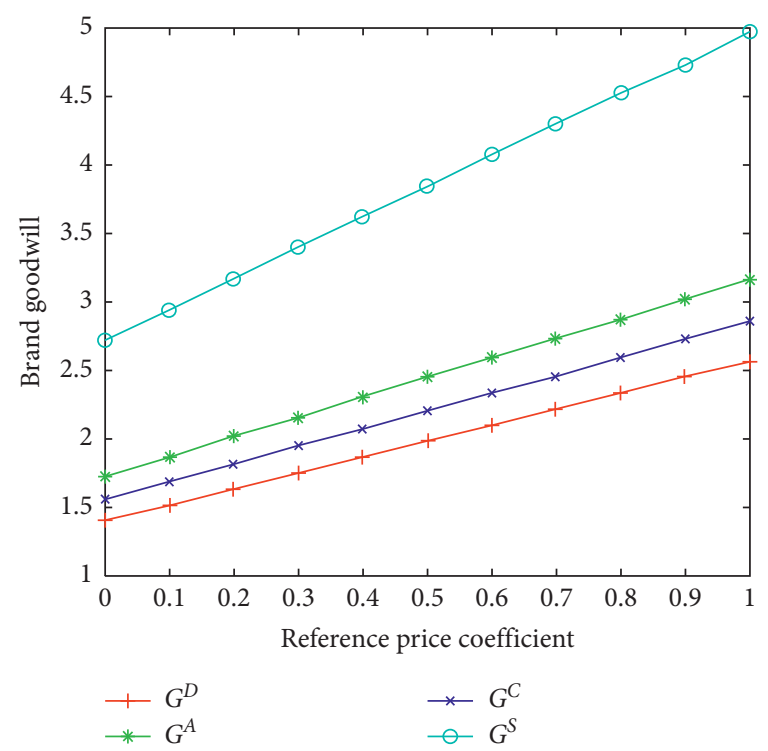

FIgURE 3: The impact of consumer reference effect on brand goodwill.

making still maintains the best level. The consumer's reference effect $\beta$ has a positive correlation with the impact of changes in product brand goodwill. The higher the consumer's reference price effect $\beta$, the higher the brand goodwill $G(t)$.

From Figures 4 and 5, we can see that the reference price effect of consumers has a positive correlation with the effort level and publicity level of building materials manufacturers and retailers. The effort level and publicity level still have the highest effect under the centralized decision-making model. Building materials retailer's commitment to costs can improve the level of efforts of manufacturers, improve product quality, and achieve Pareto improvement. 


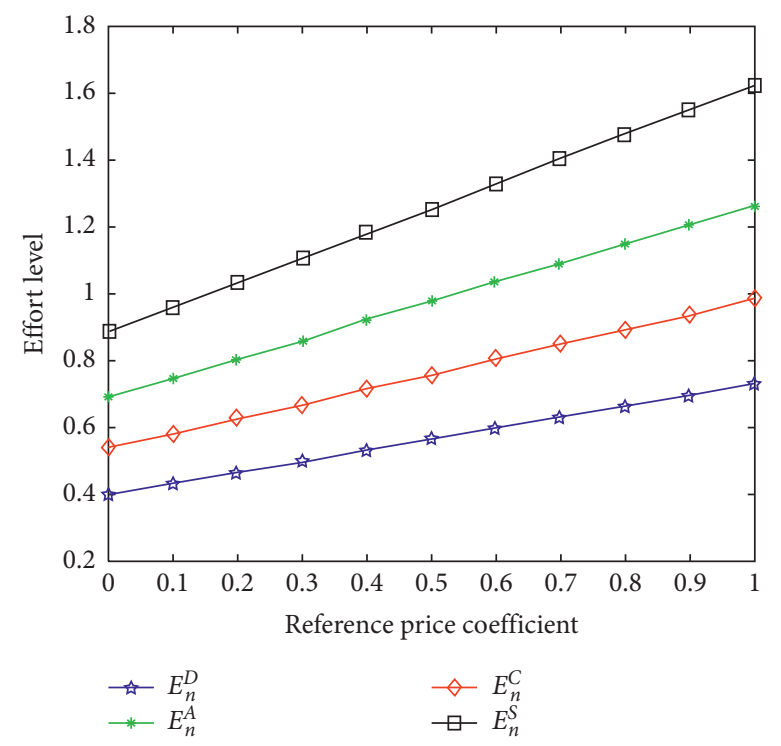

Figure 4: The impact of consumer reference price effects on effort level.

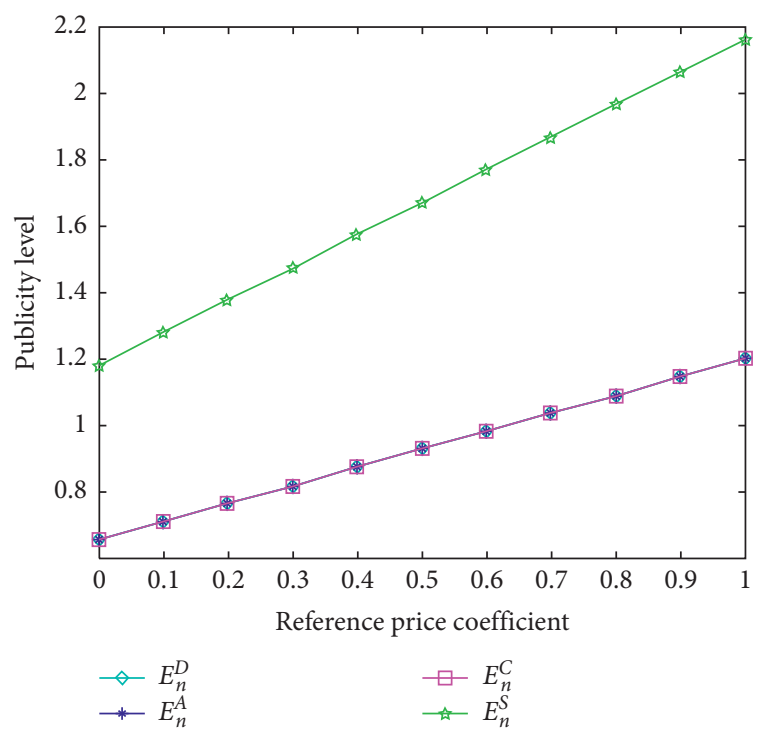

FIGURE 5: The impact of consumer reference price effects on the level of publicity.

\section{Conclusion}

With the help of differential game model, this article incorporates manufacturer's concerns about fairness in benefit distribution and consumer's reference price effects into the building materials market supply chain decisionmaking and cooperation issues. Under different decisionmaking models, different decision-making factors of manufacturers and retailers are discussed, and how to promote supply chain cooperation to achieve a win-win situation is also discussed. By constructing the NASH noncooperative game, the Stackelberg game model with cost sharing, the Stackelberg game model with fair concerns about the distribution of benefits, and the centralized decision-making model are obtained. The optimal decision-making model, brand goodwill dynamic model, and supply chain effect model of manufacturer and retailer in four cases are obtained. Finally, the sensitivity of related parameters was tested through simulation analysis, and the final conclusions are as follows.

First, under the centralized decision-making model, building materials manufacturers and retailers can put a higher level of effort and publicity to achieve Pareto optimal and achieve the best stable value of brand goodwill. This is because, under the centralized decision-making model, the overall benefit of the supply chain is the common goal of both parties, effectively mobilizing the enthusiasm of manufacturers and retailers. Considering the effect of consumer's reference prices will help promote the production and supply chain to realize a virtuous circle of "increasing resource input-competing for market shareincreasing corporate effect."

Second, building materials manufacturer's concerns about fairness in the distribution of benefits not only are detrimental to the improvement of their own interests but also reduce their own efforts and production effects and affect the overall effect of the supply chain. However, the fairness concern of the manufacturer will not affect the publicity level of the retailer, because the fairness concern of the building material manufacturer is a personal subjective thought and cannot be understood by the retailer. When retailers make decisions, they will assume that the fairness concerns of manufacturers are zero. Therefore, the unilateral fairness concerns of manufacturers will have a negative impact on the overall efficiency of the supply chain, and it is necessary to adjust their strategies to suppress the damage [22].

Third, building materials retailers will take the initiative to bear part of the manufacturer's costs only when their own marginal profit is higher than half of the manufacturer's own marginal profit, and the ratio is positively related to its own 
marginal profit and inversely proportional to the marginal profit of the building material manufacturer. Cost-bearing helps manufacturers reduce cost pressures, so that more funds can be invested in product research and development to achieve the purpose of improving product quality and achieving better brand effects. Building materials retailers can make up for the cost through the increase of sales, so as to improve their own effect level and achieve a win-win situation.

Although this article considers the impact of fairness concerns on supply chain decision-making and effects, it does not consider the evolutionary game between supply chain companies. Building materials retailers will understand the fairness concern psychology of building materials manufacturers over time, so as to change enterprise decision-making and seek higher interests. In the future, we will further discuss the evolutionary game of decision-making and effect among supply chain enterprises over time.

\section{Appendix}

Proof of Theorem A

After time $t$, the optimal value function of the profit of the producer and the retailer is as follow:

$$
\begin{aligned}
& J_{N}^{D *}\left(E_{n}\right)=e^{-\rho t} V_{N}^{D}(G, D), \\
& J_{M}^{D *}\left(E_{m}\right)=e^{-\rho t} V_{M}^{D}(G, D) .
\end{aligned}
$$

The sufficient conditions for static feedback equilibrium can be assumed. The optimal value function has a HamiltonJacobi-Bellman equation for any $G>0, R>0$, as follows:

$$
\rho V_{N}^{D}(G, R)=\max _{E_{n}}\left[\pi_{n}(a-b p+\alpha G+\beta(R-P))-\frac{1}{2} k_{1} E_{n}^{2}+V_{N G}^{D^{\prime}}\left(r_{n} E_{n}+r_{m} E_{m}-\delta G\right)+V_{N R}^{D^{\prime}}(\theta(P-R)+\lambda G)\right]
$$

Take the partial derivative of the manufacturer's effort level on the right side of the above formula and set it to zero to obtain the first-order condition,

$$
E_{n}^{D}=\frac{r_{n} V_{N G}^{D^{\prime}}}{k_{1}}
$$

Similarly, after time $t$, the profit optimal value function of building materials retailers also satisfies the HJB equation.

$$
\rho V_{M}^{D}(G, R)=\max _{E_{m}>0}\left[\pi_{m}(a-b p+\alpha G+\beta(R-P))-\frac{1}{2} k_{1} E_{m}^{2}+V_{M G}^{D^{\prime}}\left(r_{n} E_{n}+r_{m} E_{m}-\delta G\right)+V_{M R}^{D^{\prime}}(\theta(P-R)+\lambda G)\right]
$$

Find the partial derivative of $E_{m}$ on the right side of the above formula and set it to zero to obtain the first-order condition.
By substituting $E_{n}^{D}$ and $E_{m}^{D}$ into the optimal value functions of building materials manufacturers and retailers, the authors can get the following results:

$$
\begin{aligned}
& \rho V_{N}^{D}=G\left(\pi_{n} \alpha-\delta V_{N G}^{D^{\prime}}+\lambda V_{N R}^{D^{\prime}}\right)+R\left(\pi_{n} \beta-\theta V_{N R}^{D^{\prime}}\right)+\pi_{n}(a-b p-\beta p)+\frac{\left(r_{n} V_{N G}^{D^{\prime}}\right)^{2}}{2 k_{1}}+\frac{r_{m}^{2} V_{N G}^{D^{\prime}} V_{M G}^{D^{\prime}}}{k_{2}}+\theta P V_{N R}^{D^{\prime}}, \\
& \rho V_{M}^{D}=G\left(\pi_{m} \alpha-\delta V_{M G}^{D^{\prime}}+\lambda V_{M R}^{D^{\prime}}\right)+R\left(\pi_{m} \beta-\theta V_{M R}^{D^{\prime}}\right)+\pi_{M}(a-b p-\beta p)+\frac{\left(r_{m} V_{M G}^{D^{\prime}}\right)^{2}}{2 k_{2}}+\frac{r_{n}^{2} V_{N G}^{D^{\prime}} V_{M G}^{D^{\prime}}}{k_{1}}+\theta P V_{M R}^{D^{\prime}}
\end{aligned}
$$

Therefore, it can be assumed that $V_{N}^{D}(G, R)=n_{1} G+n_{2} E+$ $n_{3}$ and $V_{M}^{D}(G, R)=m_{1} G+m_{2} E+m_{3}$, where $n_{1}, n_{2}, n_{3}, m_{1}$, $m_{2}$, and $m_{3}$ are constants, according to the method of undetermined coefficients. The following formula can be obtained: 


$$
\begin{aligned}
& \left\{\begin{array}{l}
n_{1}=\frac{\pi_{n}}{\rho+\delta} \alpha+\frac{\lambda \beta}{\rho+\theta}, \\
n_{2}=\frac{\pi_{n} \beta}{\rho+\theta}, \\
n_{3}=\frac{\pi_{n}-a-b p-\beta p}{\rho}+\frac{\theta p \pi_{n} \beta}{\rho(\rho+\theta)}+\frac{r_{n}^{2} \pi_{n}^{2}}{2 k_{1} \rho(\rho+\delta)}\left(\alpha+\frac{\lambda \beta}{\rho+\theta}\right)^{2}+\frac{r_{m}^{2} \pi_{m}^{2}}{2 k_{2} \rho(\rho+\delta)}\left(\alpha+\frac{\lambda \beta}{\rho+\theta}\right)^{2}, \\
m_{1}=\frac{\pi_{m}}{\rho+\delta} \alpha+\frac{\lambda \beta}{\rho+\theta}, \\
m_{2}=\frac{\pi_{m} \beta}{\rho+\theta}, \\
\qquad \begin{array}{l}
\rho \\
m_{m}(a-b p-\beta p)
\end{array}+\frac{\theta p \pi_{m} \beta}{\rho(\rho+\theta)}+\frac{r_{m}^{2} \pi_{m}^{2}}{2 k_{2} \rho(\rho+\delta)^{2}}\left(\alpha+\frac{\lambda \beta}{\rho+\theta}\right)^{2}+\frac{r_{m}^{2} \pi_{n} \pi_{m}}{2 k_{2} \rho(\rho+\delta)}\left(\alpha+\frac{\lambda \beta}{\rho+\theta}\right)^{2} .
\end{array}\right.
\end{aligned}
$$

From this, the effort level $E_{n}^{D^{*}}$ of the manufacturer and the level $E_{m}^{D^{*}}$ of the retailer can be derived.

Then, substituting $E_{n}^{D^{*}}$ and $E_{m}^{D^{*}}$ into equation (1) of the dynamic model of brand goodwill, the optimal trajectory model of brand goodwill can be obtained, as shown in equation (6), and Theorem 1 is verified.

\section{Data Availability}

The data used to support the findings of this study are available from the corresponding author upon request.

\section{Conflicts of Interest}

The authors declare that they have no conflicts of interest.

\section{Acknowledgments}

This work was partly supported by the Major Projects of Applied Research on Philosophy and Social Sciences in Henan Universities (no. 2020-YYZD-02), the General Project of Humanities and Social Science Research of Henan Education Department (no. 2021-ZZJH-020), the Philosophy and Social Science Planning Project of Henan Province (no. 2020BJJ041), and the Key Scientific Research Projects of Higher Education Institutions in Henan Province (no. 21A520021).

\section{References}

[1] R. S. Winer, "A reference price model of brand choice for frequently purchased products," Journal of Consumer Research, vol. 13, no. 1, pp. 250-256, 1986.

[2] Z. Lin, "Price promotion with reference price effects in supply chain," Transportation Research Part E: Logistics and Transportation Review, vol. 85, pp. 52-68, 2016.

[3] A. Mehra, S. Sajeesh, and S. Voleti, "Impact of reference prices on product positioning and profits," Production and Operations Management, vol. 29, no. 4, pp. 882-892, 2020.
[4] R. Chenavaz, "Dynamic quality policies with reference quality effects," Applied Economics, vol. 49, no. 32, pp. 3156-3162, 2017.

[5] A. Gavious and O. Lowengart, "Price-quality relationship in the presence of asymmetric dynamic reference quality effects," Marketing Letters, vol. 23, no. 1, pp. 137-161, 2012.

[6] Y. Malekian and M. R. Barzoki, "A game theoretic approach to coordinate price promotion and advertising policies with reference price effects in a two-echelon supply chain," Journal of Retailing and Consumer Services, vol. 51, pp. 114-128, 2016.

[7] J. Xu and N. Liu, "Research on closed loop supply chain with reference price effect," Journal of Intelligent Manufacturing, vol. 28, no. 1, pp. 51-64, 2017.

[8] T.-P. Hsieh and C.-Y. Dye, "Optimal dynamic pricing for deteriorating items with reference price effects when inventories stimulate demand," European Journal of Operational Research, vol. 262, no. 1, pp. 136-150, 2017.

[9] S. C. Zhang, J. Zhang, and J. Shen, "A joint dynamic pricing and production model with asymmetric reference price effect," Journal of Modern Dynamics, vol. 15, no. 2, pp. 667-688, 2018.

[10] J. H. He, Y. Lei, and X. Fu, “Do consumer's green preference and the reference price effect improve green innovation? A theoretical model using the food supply chain as a case," International Journal of Environmental Research and Public Health, vol. 16, no. 24, pp. 124-138, 2019.

[11] D. Kahneman, J. L. Knetsch, and R. Thaler, "Fairness as a constraint on profit seeking: entitlements in the market," The American Economic Review, vol. 76, no. 4, pp. 728-741, 1986.

[12] E. Katok and V. Pavlov, "Fairness in supply chain contracts: a laboratory study," Journal of Operations Management, vol. 31, no. 3, pp. 129-137, 2013.

[13] T. H. Cui, J. S. Raju, and Z. J. Zhang, "Fairness and channel coordination," Management Science, vol. 53, no. 8, pp. 532541, 2017.

[14] P. Ma, K. W. Li, and Z.-J. Wang, "Pricing decisions in closedloop supply chains with marketing effort and fairness concerns," International Journal of Production Research, vol. 55, no. 22, pp. 6710-6731, 2017. 
[15] L. Zhang, H. Zhou, Y. Liu, and R. Lu, "Optimal environmental quality and price with consumer environmental awareness and retailer's fairness concerns in supply chain," Journal of Cleaner Production, vol. 213, pp. 1063-1079, 2019.

[16] Q.X. Li, X. Chen, and Y. Huang, "The stability and complexity analysis of a low-carbon supply chain considering fairness concern behavior and sales service," International Journal of Environmental Research and Public Health, vol. 16, no. 15, pp. 277-284, 2019.

[17] X.-X. Zheng, Z. Liu, K. W. Li, J. Huang, and J. Chen, "Cooperative game approaches to coordinating a three-echelon closed-loop supply chain with fairness concerns," International Journal of Production Economics, vol. 212, pp. 92-110, 2019.

[18] J. Zhang, Q. Gou, L. Liang, and Z. Huang, "Supply chain coordination through cooperative advertising with reference price effect," Omega, vol. 41, no. 2, pp. 345-353, 2013.

[19] F. E. Ouardighi, "Supply quality management with optimal wholesale price and revenue sharing contracts: a two-stage game approach," International Journal of Production Economics, vol. 156, pp. 260-268, 2014.

[20] G. Fibich, A. Gavious, and O. Lowengart, "The dynamics of price elasticity of demand in the presence of reference price effects," Journal of the Academy of Marketing Science, vol. 33, no. 1, pp. 66-78, 2005.

[21] J. Zhang, W. y. Kevin Chiang, and L. Liang, "Strategic pricing with reference effects in a competitive supply chain," Omega, vol. 44, pp. 126-135, 2014.

[22] Z. Liu, K. W. Li, B.-Y. Li, J. Huang, and J. Tang, "Impact of product-design strategies on the operations of a closed-loop supply chain," Transportation Research Part E: Logistics and Transportation Review, vol. 124, no. 124, pp. 75-91, 2019. 